\title{
Originals
}

\section{Improvement of insulin sensitivity and cardiovascular outcomes in the JCR:LA-cp rat by D-fenfluramine}

\author{
J.C. Russell ${ }^{1}$, P.J. Dolphin ${ }^{2}$, S. E. Graham ${ }^{1}$, R.M. Amy ${ }^{3}$, D. N. Brindley ${ }^{4}$ \\ ${ }^{1}$ Department of Surgery, University of Alberta, Edmonton, Alberta, Canada \\ ${ }^{2}$ Department of Biochemistry, Dalhousie University, Halifax, Nova Scotia, Canada \\ ${ }^{3}$ British Columbia Cancer Agency, Vancouver, British Columbia, Canada \\ ${ }^{4}$ Department of Biochemistry (Signal Transduction Laboratories), University of Alberta, Edmonton, Alberta, Canada
}

Summary Obese male rats of the JCR:LA-cp strain are insulin resistant, normoglycaemic, hypertriglyceridaemic, and atherosclerosis-prone. Such rats were treated from 6 to 39 weeks of age with $5 \mathrm{mg}$. $\mathrm{kg}^{-1} \cdot \mathrm{day}^{-1}$ of D-fenfluramine. The treatment normalised food intake, after 20 weeks of age, to that of lean control animals. At 39 weeks, treated rats weighed about $650 \mathrm{~g}$ compared to $800 \mathrm{~g}$ for untreated $\mathrm{cp} / \mathrm{cp}$ rats and $400 \mathrm{~g}$ for $+/+$ controls. Fasting plasma glucose and triglyceride levels were not significantly affected; however, fasting insulin concentrations were lower and the size and volume density of the hyperplastic islets of Langerhans were markedly reduced. The severity of raised atherosclerotic lesions on the aortic arch was decreased by $39 \%(p<0.01)$. Concomitantly, the occurrence of mature, scarred ischaemic myocardial lesions was virtually abolished $(p<0.01)$. Severe food restriction of the obese rats to normalise body weights to those of lean controls reduced plasma insulin and triglyceride concentrations at 26 weeks of age, but without a significant reduction in the frequency of myocardial lesions. Rats (with established insulin resistance) were treated from 6 to 12 weeks of age with $2.5 \mathrm{mg} \cdot \mathrm{kg}^{-1} \cdot \mathrm{day}^{-1}$ of D-fenfluramine. Insulin-mediated glucose turnover during a euglycaemic insulin clamp was strongly increased $(p<0.05)$. Rats treated from 3 weeks of age (before development of the insulin resistance) showed a significant delay in the development of hyperinsulinaemia and a reduced postprandial increase in plasma insulin. In contrast, restriction of food to that consumed by rats treated with D-fenfluramine did not decrease post-absorptive hyperinsulinaemia. D-fenfluramine treatment markedly improved the maximum relaxant response of aortic rings to acetylcholine, indicating improvement of the defective endothelium-derived relaxation factor system. A matched-food restriction regimen had no effect on vascular relaxation. D-fenfluramine treatment thus improved insulin sensitivity and had anti-atherosclerotic and cardioprotective effects in the presence of continuing obesity and hyperlipidaemia. The results are consistent with the protection of the function and integrity of the vessel wall associated with a decreased hyperinsulinaemia. The results emphasise the importance of focussing treatment of the metabolic syndrome (obesity/insulin resistance/hyperlipidaemia) on improving insulin sensitivity and glycaemic control rather than on the simple normalisation of body weight. [Diabetologia (1998) 41: 380-389]

Keywords Insulin resistance, atherosclerosis, JCR:LA-cp rat, endothelium-dependent relaxation factor, D-fenfluramine.
Received: 25 July 1997 and in final revised form: 25 November 1997

Corresponding author: Dr J.C. Russell, Department of Surgery, 275 Heritage Medical Research Centre, University of Alberta, Edmonton, Alberta T6G 2S2, Canada

Abbreviations: 5-HT, 5-Hydroxytryptamine; EDRF, endothelium-dependent relaxation factor; $\mathrm{HbA}_{1 \mathrm{c}}$, haemoglobin $\mathrm{A}_{1 \mathrm{c}}$; NIDDM, non-insulin-dependent diabetes mellitus.
Upper body (android) obesity, in which there are excessive deposits of visceral adipose tissue, is linked to insulin resistance, non-insulin-dependent diabetes mellitus (NIDDM), hypertension, and dyslipidaemia, particularly hypertriglyceridaemia [1, 2]. This combination of risk factors for atherosclerosis is often referred to as "syndrome ,X" or the "metabolic syndrome" $[1,2]$. The condition is associated 
with an increased incidence of coronary artery disease and stroke. Effective treatment for the metabolic syndrome is therefore an important element of the efforts to limit the incidence of cardiovascular disease.

D-fenfluramine offers such a possible treatment [3-7], causing release of 5-hydroxytryptamine (5HT) in the hypothalamus, increasing satiety, and therefore decreasing continued food intake $[1,3]$. It also helps to control endocrine balance. Long-term treatment with D-fenfluramine diminishes the duration of glucocorticoid release and the rise of circulating fatty acids in response to stress stimuli [3]. This serotoninergic action of D-fenfluramine may improve insulin sensitivity, in part, by preventing a counter-regulation by fatty acids and cortisol, accounting for the beneficial effects on glucose homeostasis and its hypolipidaemic effects $[1,2,6,7]$. In obese humans, D-fenfluramine reduces blood levels of glucose, insulin, C-peptide, and total cholesterol [8-11] without dietary restriction [8] and improves glucose tolerance without weight loss [3, 4]. Glycaemic control and $\mathrm{HbA}_{1 \mathrm{c}}$ were also improved after treating NIDDM patients with D-fenfluramine [10, 11]. D-fenfluramine therefore decreases the major risk factors associated with the metabolic syndrome and may also decrease the progression from insulin resistance to overt diabetes and cardiovascular disease $[5,12]$.

The JCR:LA-cp rat is one of several strains incorporating the autosomal recessive $c p$ gene isolated by Koletsky [13, 14]. Homozygous cp/cp rats develop the metabolic syndrome in an extreme form, with marked obesity, insulin resistance, and VLDL hyperlipidaemia [15-18]. There is also a vasculopathy that is reflected in an impairment of the endothelium-dependent relaxation factor (EDRF) mechanism and hyperactivity of the vascular smooth muscle cells [19, 20]. Male $\mathrm{cp} / \mathrm{cp}$ rats are unique in the spontaneous development of atherosclerosis and ischaemic myocardial lesions [21-24]. Vascular lesions of major arteries show all the elements seen in mature lesions in both humans and other animal models. These include adherent macrophages, endothelial desquamation, and well-developed, raised intimal lesions. The $\mathrm{cp} / \mathrm{cp}$ rat is not highly hypercholesterolaemic, and thus the vascular lesions are less extreme than those seen in cholesterol-fed rabbits or in patients with familial hypercholesterolaemia. The lesions are consistent with the diabetic vasculopathy and lipid-rich arterial lesions have been demonstrated (Richardson and Russell, unpublished observations). Other strains of rats incorporating the $c p$ gene or the other "obese" rat gene, $f a$, do not develop atherosclerosis or myocardial lesions [21, 22]. Male JCR:LA-cp rats provide a valuable model for studying mechanisms for long-term cardioprotection and reduction of beta-cell hyperplasia that are, at best, very difficult to measure in patients. We report here on the beneficial effects of $\mathrm{D}$-fenfluramine treatment on these parameters in this animal model.

The experiments consisted of short-term treatment, initiated either before (Series A) or after (Series $\mathrm{B})$ the establishment of the insulin resistance, and long-term treatment (Series C and D) of rats with established insulin resistance.

Series A: Rats, $+/+$ control, $\mathrm{cp} / \mathrm{cp}$ control, $\mathrm{cp} / \mathrm{cp}$ D-fenfluramine-treated, and $\mathrm{cp} / \mathrm{cp}$ food-restricted groups, were treated from weaning at 3 weeks of age to 12 weeks. Plasma insulin was measured in the normal fed state over the period, and at 12 weeks a meal tolerance test was performed.

Series B: Rats were treated from 6 to 12 weeks of age. Plasma insulin and glucose (fasting), insulin-mediated glucose turnover, EDRF (nitric oxide-mediated) vascular relaxation, and whole serum total lipid profiles were determined.

Series C: Rats, $+/+$ control, $\mathrm{cp} / \mathrm{cp}$ control, and D-fenfluramine-treated, were treated from 6 to 39 weeks of age. Plasma insulin and glucose (fasting), whole serum total lipid profile, pancreatic morphology (islet size and volume density), severity score of aortic arch lesions, and frequency of myocardial lesions were determined.

Series D: Rats (cp/cp freely fed control and cp/cp food-restricted to normalise body weights) were used to measure the frequency of myocardial lesions at 26 weeks of age.

\section{Animals and methods}

Animals. Male JCR:LA-cp rats $(+/+$ and cp/cp) were raised at the University of Alberta as previously described [25]. At 6 weeks of age, the rats were housed separately. Food, Wayne Rodent Blox (Harlan Sprague Dawley Inc., Madison, Wis., USA), was available at all times. D-fenfluramine (Institut de Recherches Internationales Servier, Courbevoie, France) was added to the drinking water [5], at an average dose of either 2.5 or $5 \mathrm{mg} \cdot \mathrm{kg}^{-1} \cdot \mathrm{day}^{-1}$. Blood sampling and killing were performed on fasted animals in the first half of the light period. Care and treatment of the rats conformed to the Canadian Council on Animal Care guidelines and were subject to prior institutional approval.

Short-term physiological and metabolic studies. Series $A$ male $\mathrm{cp} / \mathrm{cp}$ rats were treated with $2.5 \mathrm{mg} / \mathrm{kg}$ D-fenfluramine from 3 weeks of age, together with pair-fed and ad libitum fed controls ( $n=6$, each group), to assess the development of the hyperinsulinaemic state and insulin sensitivity as measured in a meal tolerance test. Rats were maintained on a reversed light cycle to facilitate study and handling during the active portion (dark phase) of their diurnal cycle. Animals were conditioned to blood sampling from the tip of the tail. Samples were taken $3 \mathrm{~h}$ into the dark period in the fed state at intervals up to 12 weeks of age and insulin levels were measured. Meal toler- 


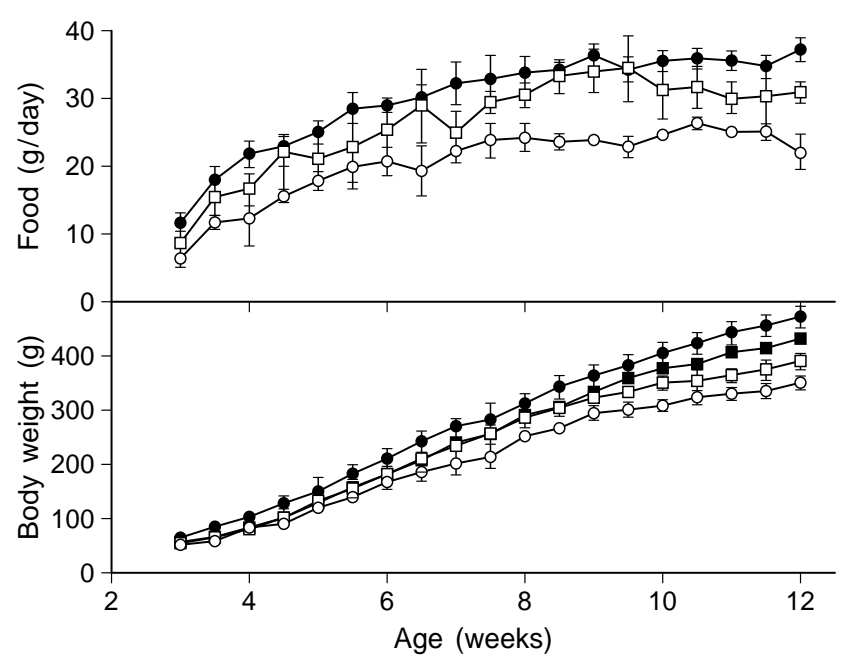

Fig. 1. Food consumption and body weights of male rats. Values are mean \pm SD for 6 rats in each group, with D-fenfluramine treatment from 3 weeks of age. $\bigcirc+/+$ control; $\mathrm{cp} /$ cp control; $\square$ cp/cp D-fenfluramine-treated at $2.5 \mathrm{mg}$. $\mathrm{kg}^{-1} \cdot \mathrm{day}^{-1} ; \square \mathrm{cp} / \mathrm{cp}$ pair-fed to the D-fenfluramine-treated group

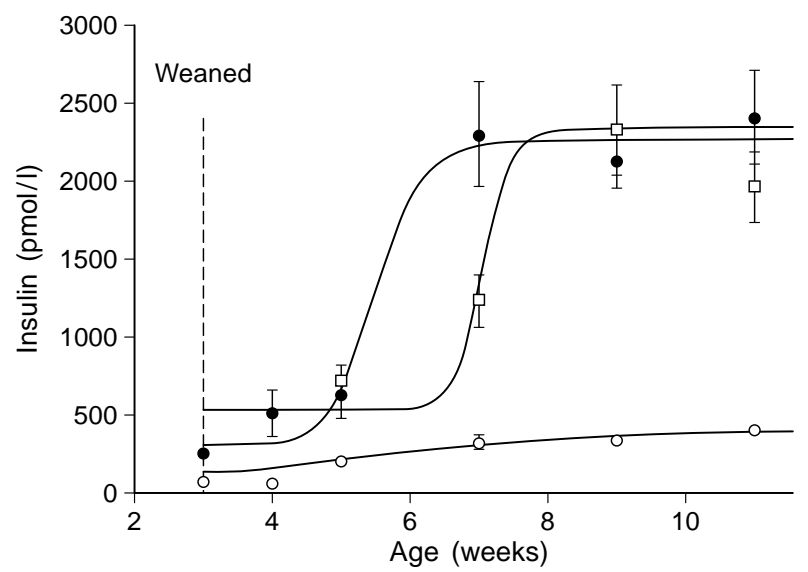

Fig. 2. Plasma insulin concentrations in male rats in the postabsorptive (fed) state, $3 \mathrm{~h}$ into the dark phase of the diurnal cycle. Values are mean \pm SD, 6 rats in each group. $\bigcirc+1+$ control; $\mathrm{cp} / \mathrm{cp}$ control; $\square \mathrm{cp} / \mathrm{cp}$ D-fenfluramine-treated from 3 weeks of age at $2.5 \mathrm{mg} \cdot \mathrm{kg}^{-1} \cdot \mathrm{day}^{-1}$. The shift in age of the increase in insulin of $\mathrm{D}$-fenfluramine-treated rats compared to $\mathrm{cp} / \mathrm{cp}$ controls was significant $(p<0.001)$

ance tests were performed at 12 weeks of age, $3 \mathrm{~h}$ into the dark phase of the diurnal cycle after $16 \mathrm{~h}$ of food deprivation. A 5-g pellet of rat chow was given to each rat and was consumed immediately. Blood was sampled from the tail and assayed for glucose and insulin.

Rats for Series $B$ were treated with $2.5 \mathrm{mg} / \mathrm{kg}$ D-fenfluramine from 6 to 12 weeks of age. At 11 weeks the rats were bled from the tail $(1.0 \mathrm{ml})$ and serum lipids were assayed as described below. At 12 weeks the rats were subjected to a euglycaemic hyperinsulinaemic clamp [24]. Halothane-anaesthetised rats were fitted with cannulas in the right femoral artery for blood sampling and in the left femoral vein for infusions. $\left[1-{ }^{3} \mathrm{H}\right]$ glucose in physiological saline was infused at $0.16 \mu \mathrm{Ci} /$ min throughout, and glucose concentrations and ${ }^{3} \mathrm{H}$ radioactivity were measured to calculate glucose turnover. After 45 min insulin was infused at a rate that varied from rat to rat, up to 3 $\mathrm{pmol} / \mathrm{min}$. Plasma glucose was measured every $5 \mathrm{~min}$, and unlabelled glucose $(0.125 \mathrm{~g} / \mathrm{l})$ was infused as required to maintain euglycaemia. Once a steady-state plasma glucose concentration had been maintained for $15 \mathrm{~min}$, samples were again taken for the measurement of ${ }^{3} \mathrm{H}$, glucose, and insulin. The measured steady-state plasma insulin concentrations achieved for rats within each group covered the range from baseline to $500 \mathrm{mmol} / \mathrm{l}$ (as described previously [18]) and were used to construct insulin dose-response curves for the group. The dose-response curve for glucose turnover was calculated from the entire data set using the ALLFIT program described below, yielding the turnover at basal insulin concentrations and maximum turnover (plateau at high insulin levels). Use of [1${ }^{3} \mathrm{H}$ ]glucose yields results that include a large component of the hepatic glucose uptake in the values obtained for glucose turnover, an important factor in the presence of profound peripheral insulin resistance [18].

Separate groups of rats were used for the study of the EDRF (nitric oxide) response of aortic rings using acetylcholine, an inducer of endothelial nitric oxide release [19]. Briefly, 2.5-mm wide rings of thoracic aorta were cut taking care not to damage the endothelial surface. Rings were maintained in an organ bath in Krebs' Henseleit buffer at $37^{\circ} \mathrm{C}$, bubbled with $95 \% \mathrm{O}_{2}: 5 \% \mathrm{CO}_{2}$. The rings were pretensioned to $0.5 \mathrm{~g}$ and stabilised. Contraction was induced with $10^{7}$ $\mathrm{mol} / \mathrm{l}$ noradrenaline, and the dose response to acetylcholine $\left(10^{-9}\right.$ to $\left.10^{-4} \mathrm{~mol} / \mathrm{l}\right)$ was measured. The viability of the rings and their ability to relax were assessed through their response to sodium nitrite $\left(10^{-6}\right.$ to $\left.10^{-3} \mathrm{~mol} / \mathrm{l}\right)$. Relaxant responses were expressed as percent of the contraction induced by noradrenaline.

Long-term pathology/metabolism studies. Series $C$ and $D$ longterm rats were treated with $5.0 \mathrm{mg} / \mathrm{kg}$ of D-fenfluramine from 6 weeks of age. Series D rats were food-restricted so as to achieve weight-matching with the $+/+$ control group. This required a food allocation of $15 \mathrm{~g} /$ day at 6 weeks of age, rising to $18 \mathrm{~g}$ /day by 10 weeks (Fig. 1 ). These animals were killed at 26 weeks of age. At 26 weeks (Series D) or at 39 weeks of age (Series C), rats were starved overnight and anaesthetised with halothane in $\mathrm{O}_{2}$. Blood was sampled from the left ventricle of the heart, and rats were then perfusion-fixed with $1.25 \%$ glutaraldehyde and $1.85 \%$ formaldehyde [25]. Heart, liver, adrenals, lungs, pancreas, and brain were further fixed and processed by conventional histological techniques. Heart sections were prepared [25] and examined blindly by an experienced pathologist. Lesion stages were classified as: stage 1, areas of necrosis; stage 2, areas of cell lysis with chronic inflammatory cell infiltration; stage 3 , nodules of chronic inflammatory cell infiltration; and stage 4, old, scarred lesions. The frequency of lesions obtained is highly consistent using these methods [26]. Pancreatic sections were examined, and cross-sectional areas of the islets of Langerhans and their volume densities were determined by image analysis. Five random fields of the pancreas were imaged at $4 \times$ magnification, and images were captured with a high-resolution camera (model EDC $1000 \mathrm{HR}$, Electrim Corporation, Princeton, N.J., USA). Analysis of the image files was performed with the program Mocha (Jandel Scientific, San Rafael, Calif., USA). Aortic arch samples were prepared, and lesions were identified and classified as areas of adherent fibrin, raised intimal lesions, areas of adherent macrophages, or areas of de-endothelialisation [25]. All lesions were photographed. Each type was assigned a severity score of 0 to 3 , with 0 representing the absence of any lesions and 3 repre- 


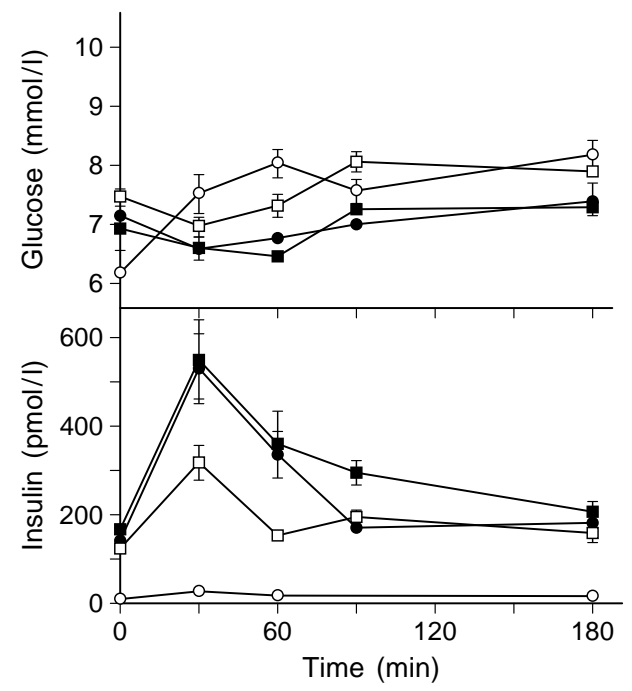

Fig. 3. Plasma glucose and insulin responses to a $5 \mathrm{~g}$ test meal of 12 -week-old male rats. Rats were treated from weaning at 3 weeks of age. Values are mean \pm SEM, 6 rats in each group. $\bigcirc+/+$ control; $\mathrm{cp} / \mathrm{cp}$ control; $\square \mathrm{cp} / \mathrm{cp}$ D-fenfluraminetreated; $\square \mathrm{cp} / \mathrm{cp}$ pair-fed to D-fenfluramine-treated. Insulin levels of D-fenfluramine-treated rats were significantly lower than those of $\mathrm{cp} / \mathrm{cp}$ controls at $30(p<0.01)$ and $60 \mathrm{~min}(p<0.025)$

Table 1. Response of glucose turnover to insulin in D-fenfluramine-treated male rats

\begin{tabular}{lll}
\hline & \multicolumn{2}{l}{ Glucose turnover $(\mathrm{mg} / \mathrm{min})$} \\
\cline { 2 - 3 } & Basal insulin & Maximal insulin \\
\hline +/+ control & $8.7 \pm 1.6$ & $19.1 \pm 2.7^{\mathrm{a}}$ \\
cp/cp control & $9.8 \pm 1.2$ & $12.5 \pm 1.8$ \\
cp/cp D-fenfluramine-treated & $8.1 \pm 1.6$ & $15.0 \pm 3.8^{\mathrm{a}, \mathrm{b}}$ \\
\hline
\end{tabular}

Values are mean \pm SD for six rats in each group, derived from a best-fit to the data set over the range of insulin concentrations using the program ALLFIT. They reflect the total glucose turnover of the plasma glucose pool. Statistical tests were performed using ALLFIT and the whole data set.

${ }^{\mathrm{a}} p<0.05$ vs basal insulin; ${ }^{\mathrm{b}} p<0.05 \mathrm{vs} \mathrm{cp} / \mathrm{cp}$ control, at maximal insulin

senting the most severe level of involvement seen in cp/cp control rats. Lesion types are distinct and were treated as separate categories, but often occur in association as they do reflect aspects of the underlying vascular disease. All samples were evaluated blindly by one individual.

Analytical techniques. Plasma glucose was measured with a rapid glucose oxidase method (Beckman Instruments, Brea, Calif., USA). Insulin was assayed with a double antibody radioimmunoassay technique (Kabi Pharmacia Diagnostics AB, Uppsala, Sweden) with rat insulin standards. Serum lipid concentrations were determined by the gas chromatographic technique of Kuksis et al. [27].

Statistical analysis. Statistical analysis was by ANOVA or Wilcoxon's rank sum test, as appropriate, with $p$ less than 0.05 for a two-tailed test taken as significant. The age dependence of insulin concentrations and the dose-response data from the euglycaemic insulin clamp and EDRF studies were analysed us-

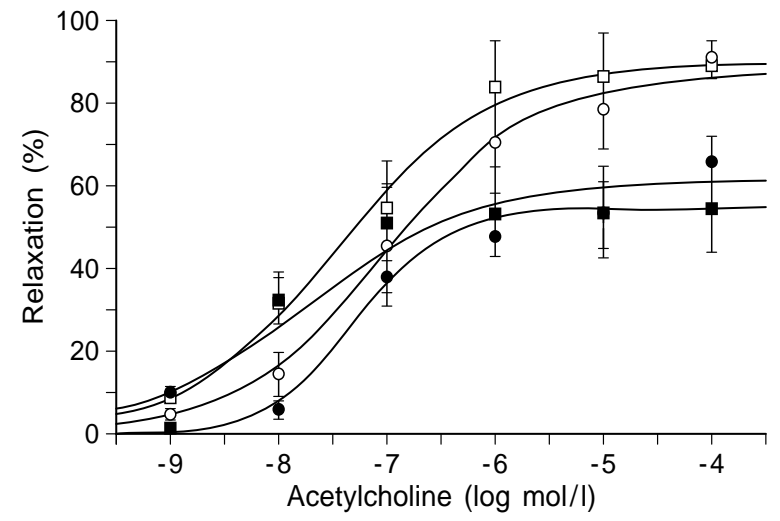

Fig. 4. Relaxation of aortic rings from 12-week-old male cp/cp rats in response to acetylcholine. $\mathrm{cp} / \mathrm{cp}$ control; $\bigcirc+/+$ control; $\square \mathrm{cp} / \mathrm{cp}$ D-fenfluramine-treated at $2.5 \mathrm{mg} \cdot \mathrm{kg}^{-1} \cdot \mathrm{day}^{-1}$; $\mathrm{cp} / \mathrm{cp}$ food-restricted to match the consumption of D-fenfluramine-treated $\mathrm{cp} / \mathrm{cp}$ rats. Animals were treated from 6 weeks of age, with 6 rats in each group. Values are mean \pm SD, and lines represent the best fit to the logistic equation by the program ALLFIT, as described in the text. Maximal relaxation was $87 \pm 9 \%$ for $+/+$ control, $54 \pm 2 \%$ for $\mathrm{cp} / \mathrm{cp}$ control, and $90 \pm 7 \%$ for $\mathrm{cp} / \mathrm{cp}$ D-fenfluramine-treated rats, respectively $(p<0.001 \mathrm{vs} \mathrm{cp/cp} \mathrm{control)}$

ing the ALLFIT program (version 2.7) [28]. This program fits the parameters of the logistic equation which describes the characteristic class of sigmoid curves commonly found in pharmacological studies. It uses the whole data set for each group and performs statistical comparisons for any of the variables (e.g. maximal response) between groups.

\section{Results}

Series $A \mathrm{cp} / \mathrm{cp}$ rats treated with D-fenfluramine from weaning at 3 weeks of age showed a modest decrease in food intake (about 13\%), whereas body weights were essentially normalised to those of the $+/+$ controls up to 6 weeks of age (Fig.1). After 6 weeks of age, both D-fenfluramine-treated rats and pair-fed controls showed body weights intermediate between those of $+/+$ and cp/cp controls. By 12 weeks of age D-fenfluramine-treated animals had lower body weights than pair-fed controls $(p<0.005)$, but not significantly greater than $+/+$ controls $(p>0.05)$. Plasma insulin concentrations in the fed state provide a sensitive index of insulin resistance, and these concentrations in the $\mathrm{cp} / \mathrm{cp}$ rats rose steeply with an age at half-maximum increase of 5.5 weeks (Fig. 2). The +1 + rats showed only a very mild increase in insulin levels, with a similar age dependence. The cp/cp rats treated with $\mathrm{D}$-fenfluramine developed an equally great hyperinsulinaemia as the $\mathrm{cp} / \mathrm{cp}$ control rats, but delayed to 7.1 weeks of age at half increase $(p<$ $0.001)$. The delay lagged the increase in body weight compared to the $+I+$ control animals (Fig. 1 ) by 1 week. Because the overall decrease in food consumption induced by D-fenfluramine in these very young 
Table 2. Fasting plasma glucose, insulin concentrations, and morphology of islets of Langerhans in D-fenfluramine-treated male rats

\begin{tabular}{|c|c|c|c|c|}
\hline & Plasma glucose $(\mathrm{mmol} / \mathrm{l})$ & Plasma insulin (mU/l) & Islet volume density & Islet size $\left(\mu \mathrm{m}^{2} \times 10^{-4}\right)$ \\
\hline & $7.32 \pm 0.61$ & $29 \pm 15$ & $0.012 \pm 0.009$ & $2.09 \pm 1.19$ \\
\hline $\mathrm{cp} / \mathrm{cp}$ control & $7.82 \pm 0.61$ & $169 \pm 81$ & $0.144 \pm 0.046$ & $10.59 \pm 2.43$ \\
\hline cp/cp D-fenfluramine-treated & $8.43 \pm 0.84$ & $100 \pm 52^{\mathrm{a}}$ & $0.058 \pm 0.033^{\mathrm{b}}$ & $5.76 \pm 2.33^{\mathrm{b}}$ \\
\hline
\end{tabular}

Values are mean \pm SD for ten 39 -week-old rats in each group.

${ }^{\mathrm{a}} p<0.05 ;{ }^{\mathrm{b}} p<0.005 \mathrm{vs} \mathrm{cp} / \mathrm{cp}$ control

Table 3. Whole serum lipid concentrations in male rats treated with D-fenfluramine

\begin{tabular}{|c|c|c|c|c|c|}
\hline & Unesterified cholesterol & Cholesteryl esters & Total cholesterol & Phospholipids & Triglycerides \\
\hline \multicolumn{6}{|l|}{12 weeks of age } \\
\hline$+/+$ control & $0.50 \pm 0.78$ & $1.11 \pm 0.17$ & $1.60 \pm 0.22$ & $0.94 \pm 0.12$ & $0.19 \pm 0.37$ \\
\hline $\mathrm{cp} / \mathrm{cp}$ control & $0.61 \pm 0.11$ & $1.64 \pm 0.47$ & $2.23 \pm 0.48$ & $2.57 \pm 0.16$ & $4.49 \pm 1.22$ \\
\hline cp/cp D-fenfluramine-treated & $0.84 \pm 0.15$ & $1.75 \pm 0.23$ & $2.59 \pm 0.37$ & $2.66 \pm 0.27$ & $4.83 \pm 0.80$ \\
\hline \multicolumn{6}{|l|}{39 weeks of age } \\
\hline +/+ control & $0.29 \pm 0.41$ & $0.93 \pm 0.17$ & $0.53 \pm 0.08$ & $0.71 \pm 0.14$ & $0.22 \pm 0.09$ \\
\hline $\mathrm{cp} / \mathrm{cp}$ control & $0.93 \pm 0.30$ & $2.75 \pm 0.91$ & $3.68 \pm 1.20$ & $2.84 \pm 0.89$ & $3.49 \pm 1.14$ \\
\hline $\mathrm{cp} / \mathrm{cp}$ D-fenfluramine-treated & $1.03 \pm 0.85$ & $3.05 \pm 2.87$ & $4.08 \pm 3.72$ & $2.82 \pm 1.75$ & $3.69 \pm 2.35$ \\
\hline
\end{tabular}

Values are $\mathrm{mmol} / \mathrm{l}$; mean \pm SD for 10 rats in each group. The samples were taken from overnight-fasted animals by tail bleed at 12 weeks of age and by cardiac puncture at 39 weeks of age. No statistical comparisons are reported of the markedly different values of the $+/+$ rats compared to the $\mathrm{cp} / \mathrm{cp}$ groups rats was small, no pair-fed group was studied. Severe reduction of food intake (to $40 \%$ less than consumed by $+/+$ control rats) delayed the age of half-maximum increase to 8.9 weeks (data not shown).

Figure 3 shows plasma glucose and insulin responses to the test meal of a $5 \mathrm{~g}$ food pellet. All rats maintained normoglycaemia after food ingestion. Lean $+/+$ controls showed only a very small postprandial increase in plasma insulin. In contrast, both $\mathrm{cp} / \mathrm{cp}$ control and $\mathrm{cp} / \mathrm{cp}$ pair-fed rats showed a sharp increase in insulin, peaking at over $500 \mathrm{pmol} / \mathrm{l}$ at 30 min. D-fenfluramine-treated rats showed similar fasting insulin levels to untreated control and pairfed $\mathrm{cp} / \mathrm{cp}$ rats, but had significantly lower insulin responses to food $(315 \mathrm{pmol} / 1, p<0.01)$.

The results of the euglycaemic insulin clamp studies on 12-week-old rats are expressed on a "per rat" basis (which is more closely related to lean body mass) rather than "per kg body weight" in view of large variations in body fat content between experimental groups (Table 1 ). The $+/+$ rats responded to maximum insulin with a greater than $100 \%$ increase in glucose turnover, while control male $\mathrm{cp} / \mathrm{cp}$ rats showed only a small, non-significant insulin-mediated increase in glucose turnover. In contrast, $\mathrm{cp} / \mathrm{cp}$ rats treated with D-fenfluramine from 6 weeks of age showed an $85 \%$ increase in glucose turnover $(p<$ $0.05)$ in response to insulin, a response that was significantly greater than that of the control rats $(p<$ $0.05)$ and was comparable to that of the $+/+$ controls.

Aortas from 12-week-old D-fenfluramine-treated rats responded more strongly to acetylcholine, with a maximum relaxation of $90 \pm 7 \%$ compared to $54 \pm 3 \%$ for control $\mathrm{cp} / \mathrm{cp}$ rats $(p<0.001)$ and $87 \pm$ $9 \%$ for $+/+$ control rats (Fig. 4 ). Aortic rings from $\mathrm{cp} / \mathrm{cp}$ rats food-restricted to match D-fenfluraminetreated $\mathrm{cp} / \mathrm{cp}$ animals showed no improvement in maximum relaxation $(57 \%)$. There was no significant difference in $\mathrm{ED}_{50}$ for acetylcholine $(36 \pm 20,53 \pm 16$, and $101 \pm 7 \mathrm{nmol} / \mathrm{l}$ for D-fenfluramine-treated, cp/cp control, and $+/+$ control rats, respectively).

Treatment of Series $C \mathrm{cp} / \mathrm{cp}$ rats, starting at 6 weeks of age when the insulin resistance is established, resulted in an immediate modest decrease $(12 \%, p<0.05)$ in food intake. While the absolute amount of food consumed increased between 6 to 8 weeks of age for D-fenfluramine-treated rats, it remained below that of $\mathrm{cp} / \mathrm{cp}$ control animals throughout. At 10-12 weeks of age food consumption decreased, and by 20 weeks of age was virtually identical to that of $+/+$ control rats (about $21 \mathrm{~g} /$ day). In comparison, $\mathrm{cp} / \mathrm{cp}$ control rats consumed above $30 \mathrm{~g} /$ day. The lower food consumption of treated rats was reflected by lower body weights $(p<0.001)$ throughout (a $32 \%$ decrease in the excess weight gain of $\mathrm{cp} /$ cp compared to $+/+$ rats at 36 weeks).

At 39 weeks of age fasting plasma glucose concentrations were not altered significantly and did not differ between $\mathrm{cp} / \mathrm{cp}$ and $+/+$ controls (Table 2 ). Plasma insulin levels were $40 \%$ lower $(p<0.05)$ in D-fenfluramine-treated rats. The extreme hyperplasia of the islets of Langerhans of cp/cp rats (Fig. $5 b$ and $c$ compared to a) was markedly reduced by D-fenfluramine treatment. Islets from treated animals were smaller (Fig. 5d) and retained a more normal archi- 

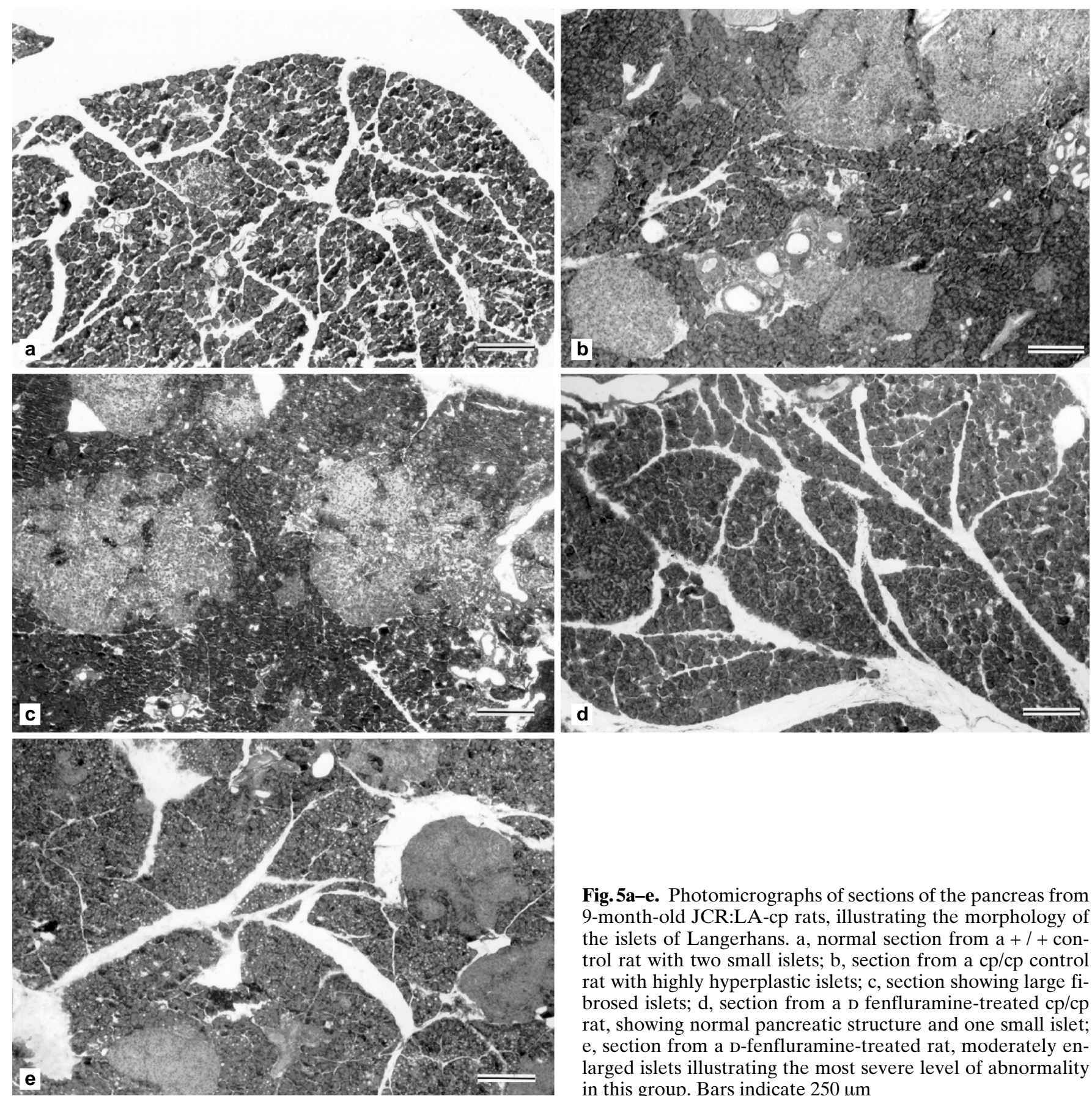

Fig. 5a-e. Photomicrographs of sections of the pancreas from 9-month-old JCR:LA-cp rats, illustrating the morphology of the islets of Langerhans. a, normal section from $\mathrm{a}+/+$ control rat with two small islets; $b$, section from a cp/cp control rat with highly hyperplastic islets; $\mathrm{c}$, section showing large fibrosed islets; d, section from a $\mathrm{D}$ fenfluramine-treated $\mathrm{cp} / \mathrm{cp}$ rat, showing normal pancreatic structure and one small islet; $\mathrm{e}$, section from a D-fenfluramine-treated rat, moderately enlarged islets illustrating the most severe level of abnormality in this group. Bars indicate $250 \mu \mathrm{m}$

tecture than those in untreated controls. Significant areas of the pancreas of treated rats were entirely normal (Fig. 5d), and even the most abnormal areas were much less affected (Fig. 5e). Treated rats did not exhibit large fibrosed islets (Fig. 5c). Volume densities of the islets of Langerhans were reduced in D-fenfluramine-treated rats, reflecting these morphological improvements and reduction in islet size (Table 2).

There were no significant changes in lipid concentrations at either 12 or 39 weeks of age (Table 3 ). The severity of raised atherosclerotic lesions on the aortic arch of the D-fenfluramine-treated rats was sig- nificantly reduced (Table 4). Figure 6 shows typical areas of the aortic arch, with raised atherosclerotic lesions from control and D-fenfluramine-treated rats. Lesions from treated rats are markedly less large and complex. The severity score for endothelial damage and adherent macrophages was unchanged, and there was a greater deposition of fibrin. Accompanying the decrease in the severity of atherosclerosis was a virtually total prevention of stage 4 (mature, scarred) myocardial lesions (Table 4). No abnormalities were found in the histological sections of the liver, adrenals, lungs, and brain from 39-week-old rats. 
Table 4. Myocardial and vascular lesions in 9-month-old male cp/cp JCR: LA-cp rats

\begin{tabular}{lllll}
\hline Aortic arch lesions & Fibrin & Raised lesions & Macrophages & De-endothelialisation \\
\hline Control & 0 & $2.75 \pm 0.71$ & $1.63 \pm 1.30$ & $0.63 \pm 0.74$ \\
D-fenfluramine-treated & $1.22 \pm 1.20$ & $1.67 \pm 1.87$ & $0.67 \pm 0.87$ & $0.67 \pm 1.00$ \\
$P$ value & $p<0.01$ & $p<0.01$ & NS & NS \\
\hline Myocardial lesions & Stage 1 & Stage 2 & Stage 3 & $1.83 \pm 1.27$ \\
\hline Control & $0.25 \pm 0.45$ & $0.25 \pm 0.45$ & $0.33 \pm 0.65$ & $0.11 \pm 0.33$ \\
D-fenfluramine-treated & $0.11 \pm 0.33$ & $0.22 \pm 0.67$ & $0.33 \pm 0.50$ & $p<0.01$ \\
$p$ value & NS & NS & NS & \\
\hline
\end{tabular}

Values are mean \pm SD of the severity score for vascular lesions and frequency of occurrence for the myocardial lesions, as described in the text. There were 10 rats in each group. Statistical

comparisons were made by the Wilcoxon rank sum test. NS, not significant

At 26 weeks of age, Series $D$ food-restricted rats, while of identical weights to $+/+$ controls, retained the obese phenotype characterised by a smaller, more rounded body shape. Fasting plasma insulin levels of 6-month-old male $\mathrm{cp} / \mathrm{cp}$ rats were reduced from $208 \pm 68$ to $68 \pm 42 \mathrm{pmol} / 1(68 \%, p<0.0005)$ compared to those of matched controls, and plasma triglycerides were decreased from $1.91 \pm 0.10$ to $0.99 \pm 0.40 \mathrm{mmol} / \mathrm{l}(56 \%, p<0.001)$. The incidence of stage 4 myocardial lesions was decreased $0.33 \pm$ 0.52 vs $1.00 \pm 0.89$ for controls, but this more modest decrease was not significant $(p>0.05)$.

\section{Discussion}

Male cp/cp rats, while highly insulin resistant and with impaired glucose tolerance, do not have fasting hyperglycaemia and are not diabetic [16]. Thus, Dfenfluramine did not decrease fasting plasma glucose concentrations (Fig.3, Table 2). The development of high insulin levels in the fed state was delayed by D-fenfluramine treatment (Fig. 2). The elevated fasting insulin levels characteristic of JCR:LA-cp rats were also decreased (about 50\%, Table 2). The hyperinsulinaemic response $30 \mathrm{~min}$ after the test meal was reduced at 12 weeks of age, whereas pair-fed rats showed no improvement (Fig. 3). At 90 to $180 \mathrm{~min}$ after the test meal, there was little difference in insulin concentrations in control and D-fenfluramine-treated rats, in agreement with the postabsorptive values (Fig. 2). The reduced insulin response to the test meal confirms improved metabolism in treated rats, permitting them to maintain normoglycaemia at lower plasma insulin levels. This is consistent with increased insulin-mediated glucose turnover and with other studies showing that D-fenfluramine improves insulin action in lowering hepatic glucose production [29, 30]. Thus, improved insulin/glucose metabolism may result largely from an improved ability of the liver to take up and metabolise glucose, for example, via the pentose phosphate pathway. After long-term treatment with D-fenfluramine there was a marked reduction in the size of the islets of Langerhans, which did not exhibit the gross morphological changes of the highly hyperplastic islets of control animals (Fig. 6). Previous short-term studies showed decreased plasma insulin in $\mathrm{cp} / \mathrm{cp}$ rats treated with D-fenfluramine [5]. These changes in the pancreas and insulin metabolism indicate that D-fenfluramine effectively improved insulin response.

Short-term treatment of male $\mathrm{cp} / \mathrm{cp}$ rats with $\mathrm{D}$ fenfluramine combined with food restriction did not reduce plasma triglyceride levels (Table 3 ). Other agents also improve insulin sensitivity without reducing plasma lipids in this experimental model [31,32]. Whereas the obesity was ameliorated in D-fenfluramine-treated rats, treated $\mathrm{cp} / \mathrm{cp}$ rats still retained about $75 \%$ of their overweight compared to the +1 + controls. D-fenfluramine reduced food intake markedly and insulin response was improved, resulting in lower overall insulin levels, especially postprandially (Fig.3). In the cp/cp rat, such decreases in circulating insulin levels correlate with reductions in cardiovascular disease $[31,32]$.

EDRF, which is most probably nitric oxide [33], is released by endothelial cells, causing vascular smooth muscle cells to relax and inhibiting vasospasm [34]. Defective EDRF responses of aortas of male cp/cp rats reflect an impaired endothelial function and vascular control [19]. This correlates with the incidence of ischaemic myocardial lesions. The marked increase in response to acetylcholine of the aortas from D-fenfluramine-treated rats is consistent with previous studies showing that increased insulin sensitivity is associated with improved cardiovascular status [35]. This suggests that vascular dysfunction, including vasospasm, may be induced by the hyperinsulinaemia associated with the metabolic syndrome. Our findings that cardioprotection is obtained with the calcium channel antagonists, nifedipine [36] and nisoldipine [37], support this hypothesis. The more marked reduction in myocardial lesions than in the severity of atherosclerosis in D-fenfluramine-treated rats may thus be due in significant measure to reduced vascular dysfunction or spasm. Such improvement in vascular relaxation is also supported by re- 


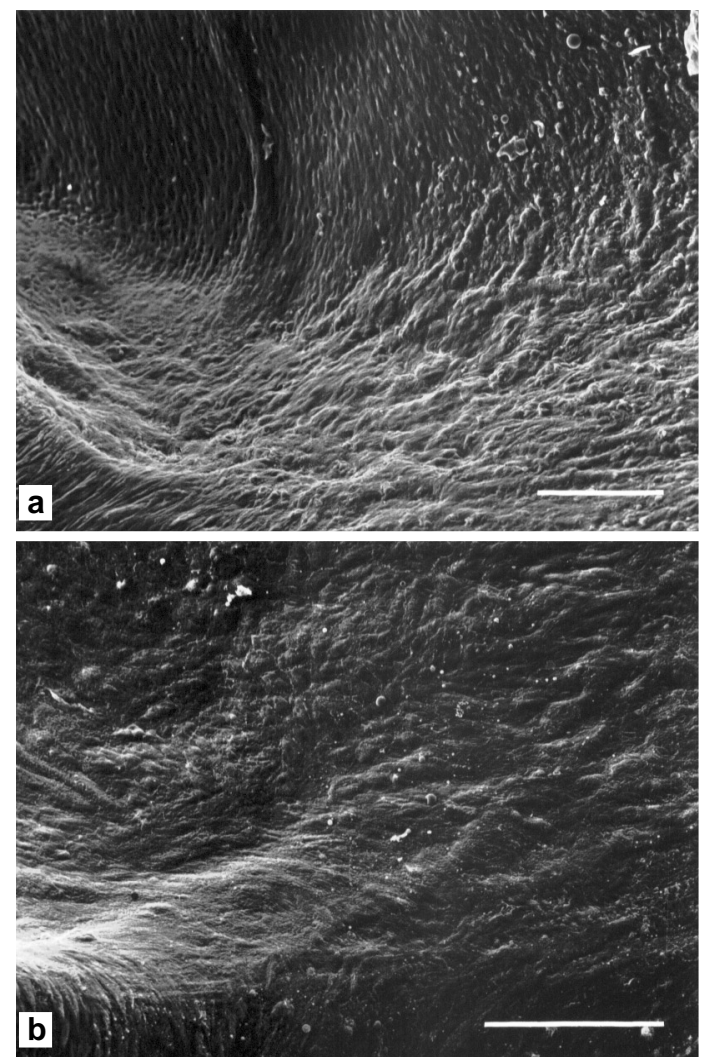

Fig.6a, b. Scanning electron micrographs of illustrative raised intimal lesions of the aortic arch from 9-month-old male rats. a, $\mathrm{cp} / \mathrm{cp}$ control, score of 3 , extensive raised lesions at the ostium of a major vessel, with adherent macrophages and some desquamation of the endothelium; b, cp/cp D-fenfluraminetreated, score of 1 , small raised lesion with abnormal endothelial cells surrounding and overlying the lesion. Bars indicate $100 \mu \mathrm{m}$

ports that D-fenfluramine has blood pressure lowering effects in obese humans $[4,10]$.

Long-term D-fenfluramine treatment of $\mathrm{cp} / \mathrm{cp}$ rats at the relatively low dose range used for rats [3-5, $30,38]$ caused a sustained reduction in voluntary food consumption similar to that of the $+/+$ control rats in the latter half of the treatment period. These doses are higher than those used therapeutically in humans because the rat metabolises and eliminates D-fenfluramine much more rapidly.

Raised intimal lesions on the aortic arch of these D-fenfluramine-treated rats were markedly reduced in size and severity. This improvement in the vessel wall was paralleled by an essential absence of advanced ischaemic myocardial lesions in 9-month-old rats (Table 4). Rats that were weight-paired to + I + animals had significant improvements in insulin status and in the reduction of plasma triglyceride concentrations. Nonetheless, even in these younger animals (26 weeks of age), in which the cumulative ischaemic damage is less advanced, the reduced frequency of myocardial lesions was less ( 70 vs $94 \%$ ) than that seen in older D-fenfluramine-treated rats, which are more severely at risk. Stage 4 (old, scarred) lesions are cumulative and would progress between 26 and 39 weeks of age in the weight-matched rats. This confirms that the metabolic and vascular improvements induced by D-fenfluramine are not simply due to reductions in food intake and obesity.

Other work demonstrated that reducing hyperinsulinaemia is more important in this animal model in providing cardioprotection than in decreasing lipid concentrations $[31,32,39]$. We suggest that the protective effect is due to reduced endothelial injury, consequent to lower insulin concentrations and lower peak levels of glucose. Even in the presence of elevated plasma lipid concentrations, this results in reduced atherogenesis. Less severe intimal damage and endothelial dysfunction also reduce abnormalities in the functioning of smooth muscle and cells of the vessel wall [19], resulting in a decrease in coronary vasospasm. Increased fibrin deposition on the aortic arches of D-fenfluramine-treated rats is inconsistent with the above findings. This may be artifactual and reflect the absence of significant observed fibrin on the aortas of the $\mathrm{cp} / \mathrm{cp}$ control group. The presence of fibrin is expected, especially since there is increased secretion of plasminogen activator inhibitor1 in male $\mathrm{cp} / \mathrm{cp}$ rats (Schneider et al., unpublished observations). The formation of the end-stage of the disease, ischaemic lesions in the heart, is a complex, multifactorial process, and the improvement in vessel wall function has been sufficient to more than offset the deleterious effects of increased fibrin deposition.

The improvements in insulin sensitivity and glucose homeostasis demonstrated in the present work are compatible with results from other experimental animal models and in obese-diabetic patients [3-5, 8-10]. Some effects could result from the anorexic action of D-fenfluramine and improved insulin action following weight loss. In the grossly hyperphagic and obese $\mathrm{cp} / \mathrm{cp}$ rats, food restriction is an important component of therapy, and it can largely account for the decrease in fasting insulin concentrations (Table 2) [5]. However, the beneficial effects of D-fenfluramine treatment in decreasing the insulin response to the test meal, in increasing maximum arterial relaxation, and in completely preventing the occurrence of scarred myocardial lesions could not be mimicked by food restriction. This confirms that $\mathrm{D}$-fenfluramine produces beneficial effects on insulin sensitivity and glucose homeostasis independent of weight loss $[3,4]$.

Out results are consistent with much of the clinical experience with D-fenfluramine. Therapeutic treatment of obesity shows relatively modest decreases in body weight unless there are also substantial changes in lifestyle, dietary composition, and exercise, but body weight alone should not be the overriding measure of efficacy. Obesity, per se, is not necessarily a risk factor for diabetes and cardiovascular disease, as in the case of gynoid obesity. Risk is associated rather 
with the insulin resistance and metabolic disturbances that are characteristic of android obesity [40]. Treatment of the male $\mathrm{cp} / \mathrm{cp}$ rats improved insulin sensitivity, decreased beta-cell hyperplasia, decreased aortic atherosclerosis, and improved vascular relaxation. Most importantly, it reduced the incidence of ischaemic myocardial lesions. These results with the $\mathrm{cp} / \mathrm{cp}$ rat provide direct evidence that longterm treatment with $\mathrm{D}$-fenfluramine provides effective protection against the progression of insulin resistance and the associated cardiovascular disease in an animal model, supporting the possibility of similar beneficial effects being obtained in humans.

Acknowledgements. This work was supported by the Institut de Recherches Internationales Servier, the Heart and Stroke Foundations of Alberta and the Northwest Territories and of Nova Scotia, the Medical Research Council of Canada, and the Canadian Diabetes Association.

\section{References}

1. Reaven GM (1988) Role of insulin resistance in human disease. Diabetes 37: 1595-1607

2. Després J-P (1994) Visceral obesity: a component of the insulin resistance dyslipidemic syndrome. Can J Cardiol 10 [Suppl B]:17B-22B

3. Arnaud O, Nathan C (1990) Antiobesity and lipid-lowering agents with antidiabetic activity. In: Bailey CJ, Flatt RP (eds) New anti-diabetic drugs. London, Smith-Gordon, pp 133-142

4. Davis R, Faulds D (1996) Dexfenfluramine: an updated review of its therapeutic use in the management of obesity. Drugs 52: 696-724

5. Brindley DN, Hales P, Al-Sieni AII, Russell JC (1992) Sustained decreases in weight and serum insulin, glucose, triacylglycerol and cholesterol in JCR:LA-corpulent rats treated with D-fenfluramine. Br J Pharmacol 105: 679-685

6. Brindley DN (1983) Phenylethylamines and their effects on the synthesis of fatty acids, triacylglycerols and phospholipids. In: Curtis-Prior PB (ed) Biochemical pharmacology of obesity. Amsterdam, Elsevier, pp 285-308

7. O'Connor HT, Richman RM, Steinbeck KS, Caterson ID (1995) Dexfenfluramine treatment of obesity: a double blind trial with post trial follow up. Int J Obes 19: 181-189

8. Anderson PH, Richelsen B, Bak J, et al (1993) Influence of short-term dexfenfluramine therapy on glucose and lipid metabolism in obese non-diabetic patients. Acta Endocrinol 128: 251-258

9. Scheen AJ, Paolisso G, Salvatore T, Lefebvre PJ (1991) Improvement of insulin-induced disposal in obese patients with NIDDM after 1-wk treatment with $d$-fenfluramine. Diabetes Care 14: 325-332

10. Stewart GO, Stein GR, Davis TME (1993) Dexfenfluramine in type II diabetes: effect on weight and diabetes control. Med J Austr 158: 167-169

11. Willey KA, Molyneaux LM, Overland JE, Yue DK (1992) The effects of dexfenfluramine on blood glucose control in patients with type 2 diabetes. Diabet Med 9: 341-343

12. Brindley DN, Russell JC (1995) Metabolic abnormalities linked to obesity: effects of dexfenfluramine in the corpulent rat. Metabolism 44 [Suppl 2]:23-27
13. Koletsky S (1973) Obese spontaneously hypertensive rats: a model for the study of atherosclerosis. Exp Mol Pathol 19: 52-60

14. Koletsky S (1975) Pathological findings and laboratory data in a new strain of obese hypertensive rats. Am J Pathol 80: $129-142$

15. Ahuja SK, Manickavel V, Amy RM, Russell JC (1987) Age-related qualitative and quantitative changes in the endocrine pancreas of the LA/N-corpulent rat. Diabetes Res 6: $137-144$

16. Russell JC, Ahuja SK, Manickavel V, Rajotte RV, Amy RM (1987) Insulin resistance and impaired glucose tolerance in the atherosclerosis-prone LA/N-corpulent rat. Arteriosclerosis 7: 620-626

17. Russell JC, Koeslag DG, Amy RM, Dolphin PJ (1989) Plasma lipid secretion and clearance in the hyperlipidemic JCR:LA-corpulent rat. Arteriosclerosis 9: 869-876

18. Russell JC, Graham S, Hameed M (1994) Abnormal insulin and glucose metabolism in the JCR:LA-corpulent rat. Metabolism 43: 538-543

19. McNamee CJ, Kappagoda CT, Kunjara R, Russell JC (1994) Defective endothelium-dependent relaxation in the JCR:LA-corpulent rat. Circ Res 74: 1126-1132

20. Absher PM, Schneider DJ, Russell JC, Sobel BE (1997) Increased proliferation of explanted vascular smooth muscle cells: a marker presaging atherogenesis. Atherosclerosis 131: 187-194

21. Russell JC, Amy RM, Michaelis IV OE, McCune SM, Abraham AA (1990) Myocardial disease in the corpulent strains of rats. In: Shafrir E (ed) Frontiers in diabetes research: lessons from animal diabetes III. Smith-Gordon, London, pp 402-407

22. Amy RM, Dolphin PJ, Pederson RA, Russell JC (1988) Atherogenesis in two strains of obese rats. The fatty Zucker and LA/N-corpulent. Atherosclerosis 69: 199-209

23. Russell JC, Amy RM (1986) Early atherosclerotic lesions in a susceptible rat model: the LA/N-corpulent rat. Atherosclerosis 60: 119-129

24. Russell JC, Amy RM (1986) Myocardial and vascular lesions in the LA/N-corpulent rat. Can J Physiol Pharmacol 64: $1270-1280$

25. Russell JC, Amy RM, Graham SE, Dolphin PJ, Wood GO, Bar-Tana J (1995) Inhibition of atherosclerosis and myocardial lesions in the JCR:LA-cp rat by $\beta, \beta^{\prime}$-tetramethylhexadecanedioic acid (MEDICA 16). Arterioscler Thromb Vasc Biol 15: 918-923

26. Russell JC, Amy RM, Graham S, Wenzel LM, Dolphin PJ (1993) Effect of castration on hyperlipidemic, insulin resistant JCR:LA-corpulent rats. Atherosclerosis 100: $113-122$

27. Kuksis A, Myher JJ, Geher K, et al (1978) Comparative determination of plasma cholesterol and triacylglycerol levels by automated gas-liquid chromatographic and autoanalyzer techniques. J Chromatogr 146: 393-412

28. De Lean A, Munson PJ, Guardabaso V, Rodbard D (1992) A users' guide to ALLFIT. National Institutes of Health, Bethesda

29. Benthem L, Scheurink AJ, Van der Leest J, Leuvenink H, Zijlstra WG, Steffens AB (1993) Effects of long-term dfenfluramine treatment on energy metabolism in rats. Eur J Pharmacol 232: 279-286

30. Picarel-Blanchot F, Bailbe D, Portha B (1994) d-Fenfluramine improves hepatic insulin action in streptozotocindiabetic rats. Eur J Pharmacol 264: 227-232

31. Russell JC, Koeslag DG, Dolphin PJ, Amy RM (1993) Beneficial effects of acarbose in the atherosclerosis-prone JCR:LA-corpulent rat. Metabolism 42: 218-223 
32. Russell JC, Amy RM, Manickavel V, Dolphin PJ (1989) Effects of chronic ethanol consumption in atherosclerosisprone JCR:LA-corpulent rat. Arteriosclerosis 9: 122-128

33. Furchgot RF, Jawadzski JV (1988) The obligatory role of endothelial cells in the relaxation of arterial smooth muscle by acetylcholine. Nature (London) 188: 373-375

34. Ignaro LJ, Byrons RE, Buga GM, Woods KS (1987) Endothelium-derived relaxing factor from pulmonary artery and vein possesses pharmacologic and chemical properties identical to those of nitric oxide radical. Circ Res 61: 866-879

35. O'Brien SF, Russell JC (1997) Insulin resistance and vascular wall function: lessons from animal models (Review). Endocrin Metab 4: 155-162

36. Russell JC, Koeslag DG, Dolphin PJ, Amy RM (1990) Prevention of myocardial lesions in JCR:LA-corpulent rats by nifedipine. Arteriosclerosis 10: 658-664
37. Russell JC, Dolphin PJ, Graham SE, Amy RM (1997) Cardioprotective and hypolipidemic effects of nisoldipine in the JCR:LA-cp rat. J Cardiovasc Pharmacol 29: 586-592

38. Arora R, Dryden S, McKibbin PE, Williams G (1994) Acute dexfenfluramine administration normalizes glucose tolerance in rats with insulin-deficient diabetes. Eur J Clin Invest 24: 182-187

39. Russell JC, Koeslag DG, Amy RM, Dolphin PJ (1991) Independence of myocardial disease in the JCR:LA-corpulent rat on plasma cholesterol concentration. Clin Invest Med 14: 288-295

40. Bjorntorp P (1990) Classification of obese patients and complications related to distribution of surplus fat. Nutrition 6: 131-137 